Eur. J. Clin. Chem. Clin. Biochem.

Vol. 29, 1991, pp. 111-114

(C) 1991 Walter de Gruyter \& Co.

Berlin - New York

\title{
Cold-Induced Changes in Plasma Norepinephrine, Epinephrine and Dopamine Concentrations in Patients with Raynaud's Phenomenon
}

\author{
By Bianca Marasini, Maria Luisa Biondi, R. Mollica, A. Del Santo and A. Agostoni \\ Clinica Medica, Ospedale S. Paolo, Università degli Studi, Milano, Italy
}

(Received August 9/November 19, 1990)

Summary: To investigate the role of the sympathetic system in Raynaud's phenomenon, which has not yet been elucidated, we measured the levels of norepinephrine, epinephrine and dopamine before, immediately and 30 min after the cold pressor test in plasma from 17 patients with primary, 6 with secondary Raynaud's phenomenon and 19 volunteers, matched for age and sex. Patients had significantly low baseline epinephrine $(0.13 \pm 0.02$ vs $0.37 \pm 0.04, \mathrm{nmol} / \mathrm{l}, \mathrm{p}<0.001$, mean \pm S. E. $)$, but normal norepinephrine and dopamine (norepinephrine: $1.77 \pm 0.16$ and $2.06 \pm 0.18$; dopamine: $0.10 \pm 0.01$ and $0.11 \pm 0.02$, patients and controls).

Immediately after the cold test norepinephrine significantly increased $(\mathrm{p}<0.001)$ in patients $(2.42 \pm 0.22)$ and controls (3.24 \pm 0.28$)$; epinephrine increased in patients $(0.18 \pm 0.02, \mathrm{p}<0.02)$; dopamine did not show any significant change $(0.13 \pm 0.01$ and $0.13 \pm 0.02$, patients and controls $)$.

In the recovery period, while norepinephrine and epinephrine returned to baseline in both groups, dopamine increased in controls $(0.21 \pm 0.04, p<0.005)$ but remained unchanged in patients $(0.11 \pm 0.01)$.

We conclude that there is no sympathetic overactivity in Raynaud's phenomenon and propose a role for circulating dopamine in post-ischaemic vasodilatation as an explanation for the particular behaviour of dopamine.

\section{Introduction}

The aetiopathogenesis of Raynaud's phenomenon is still uncertain; in particular, the role played by the sympathetic system has not yet been clearly elucidated. Data for and against the theory originally proposed by Raynaud (1) of increased activity of the sympathetic system are almost evenly divided $(2,3,4)$.

Seeking clues to the role of the sympathetic system in the mechanism of Raynaud's phenomenon, we measured the levels of norepinephrine, epinephrine and dopamine in response to the cold pressor test in plasma from patients with primary and secondary Raynaud's phenomenon.

\section{Methods}

Twenty-three patients ( 20 women and 3 men, mean age $\pm S$. E. $42 \pm 3$ years) with Raynaud's phenomenon were studied. Seventeen (15 women and 2 men, mean age $40 \pm 3$ years) had primary Raynaud's phenomenon and 6 (5 women and 1 man, mean age $49 \pm 3$ years) secondary to systemic sclerosis. The diagnosis was based on accepted criteria $(5,6)$. The mean duration of Raynaud's symptoms was $10 \pm 2$ years, with a range of 2 to 34 years. All subjects were normotensive and had no signs of cardiac involvement. The control group consisted of 19 healthy volunteers, matched for age and sex. None of the subjects, including controls, had taken any vasoactive drug during the previous ten days.

Informed consent was obtained from all subjects.

After the subjects had sat for 15 min with an indwelling catheter inserted into the antecubital vein, baseline blood samples were taken for catecholamine assay. The cold pressor test was then performed by immersing the controlateral hand in ice water for $2 \mathrm{~min}$. Blood pressure and heart rate were recorded every $15 \mathrm{~s}$. A second blood sample was taken immediately before removal of the hand from the ice water. After a 30 min recovery period, a third blood sample was taken. Plasma free catecholamines were measured by HPLC, with a coulometric detector as previously described (7).

The Student $\mathrm{t}$ test $(\mathrm{a}=0.05)$ was used to compare unpaired data. Paired data were analysed using the two-way' analysis of 
variance (ANOVA), considering diagnostic classes and experimental phases as classification factors. The phase and class effects were further examined with the multiple paired t-lest with corrected a level (0.0167).

Linear correlation cocfficients were also determined.

All data are expressed as mean $\pm S$. E.

\section{Results}

Because plasma free catecholamine concentration seems to vary less in the seated subject (8), our measurements were made after the subjects had been sitting for $15 \mathrm{~min}$.

Resting epinephrine levels were significantly low in patients $(\mathrm{p}<0.001)$, while norepinephrine and dopamine concentrations, although towards lower limits in patients, were similar in the two groups (tab. 1).

During the cold pressor test norepinephrine concentrations significantly increased $(\mathrm{p}<0.001)$ in patients $(41 \%)$ and in controls (63\%). Epinephrine concentrations showed a significant increase in patients $(p<0.02)$ but not in controls. However, absolute values of the two amines remained significantly low in patients. Dopamine levels slightly increased in patients. Thirty min after the cold pressor test, norepinephrine and epinephrine returned to baseline in the two groups. Dopamine remained unchanged in patients, but significantly lower than in controls $(p<0.05)$. In controls dopamine was found to be increased, albeit with a wide range of variability.

No significant differences were found between primary and secondary Raynaud's phenomenon in any of the plasma catecholamine levels. There were no correlations of any catecholamine levels with age or sex in either group, or with the duration of the symptoms in patients.

Resting blood pressure and heart rate were similar in the two groups, significantly increased in both groups during the cold test $(\mathrm{p}<0.001)$, and returned to baseline in the recovery period in both groups (tab. 2).

There was no correlation between haemodynamic parameters and catecholamine concentrations.

Tab. 1. Plasma norepinephrine, epinephrine and dopamine changes in 23 patients with Raynaud's phenomenon and 19 healthy controls before, immediately and $30 \mathrm{~min}$ after the cold pressor test. Values are expressed as nmol/l (mean $\pm \mathrm{S}$. E.).

\begin{tabular}{lllll}
\hline Subjects & $\mathrm{n}$ & Baseline & Cold test & Recovery \\
\hline Norepinephrine & & & & $1.99+0.16$ \\
Patients & 23 & $1.77+0.16$ & $2.42+0.22$ & $2.29+0.20$ \\
Controls & 19 & $2.06+0.18$ & $3.24+0.28$ & \\
Epinephrine & & & & $0.15+0.02$ \\
Patients & 23 & $0.13+0.02$ & $0.18+0.02$ & $0.30+0.03$ \\
Controls & 19 & $0.37+0.04$ & $0.36+0.05$ & $0.11+0.01$ \\
Dopamine & & & & $0.21+0.04$ \\
Patients & 23 & $0.10+0.01$ & $0.13+0.01$ & $\ldots .02$ \\
Controls & 19 & $0.11+0.02$ & & \\
\hline
\end{tabular}

Tab. 2. The effect of the cold pressor test on blood pressure $(\mathrm{mm} \mathrm{Hg})$ and heart rate $\left(\mathrm{min}^{-1}\right)$ in 23 patients with Raynaud's phenomenon and in 19 healthy controls.

\begin{tabular}{|c|c|c|c|c|c|c|}
\hline & \multicolumn{3}{|l|}{ Patients } & \multicolumn{2}{|l|}{ Controls } & \multirow{2}{*}{ Recovery } \\
\hline & Baseline & $\begin{array}{l}\text { Cold } \\
\text { pressure } \\
\text { test }\end{array}$ & Recovery & Baseline & $\begin{array}{l}\text { Cold } \\
\text { pressure } \\
\text { test }\end{array}$ & \\
\hline Heart rate & $71 \pm 2^{*}$ & $76 \pm 2^{*}$ & $71 \pm 2$ & $73 \pm 2$ & $78 \pm 2^{* *}$ & $72 \pm 2$ \\
\hline \multicolumn{7}{|c|}{ Arterial pressure } \\
\hline $\begin{array}{l}\text { sÿstolic } \\
\text { diastolic }\end{array}$ & $\begin{array}{r}115 \pm 2^{*} \\
77 \pm 2^{*}\end{array}$ & $\begin{array}{r}135 \pm 4^{*} \\
91 \pm 3^{*}\end{array}$ & $\begin{array}{r}114 \pm 2 \\
78 \pm 2\end{array}$ & $\begin{array}{r}120 \pm 3^{*} \\
83 \pm 2^{*}\end{array}$ & $\begin{array}{r}140 \pm 3^{*} \\
92 \pm 2^{*}\end{array}$ & $\begin{array}{r}120 \pm 3 \\
81 \pm 2\end{array}$ \\
\hline
\end{tabular}

\footnotetext{
$* \mathrm{p}<0.001$

$* * \mathrm{p}<0.002$
} 


\section{Discussion}

Although indirect estimation of sympathetic function at rest by venous plasma catecholamines is controversial $(9,10)$, examination of circulating catecholamines during various stimuli is still widely used to detect possible differences in sympathetic activity between normals and patients (11).

In this study we showed that:

1) during the cold test patients' plasma norepinephrine was within the normal range;

2) patients' plasma epinephrine levels were low at rest, but significantly increased during the cold pressor test; and

3) 30 min after the cold test, plasma dopamine significantly increased in controls but remained unchanged in patients.

The normal basal norepinephrine concentration and the normal increase of norepinephrine during the cold pressor test would indicate a normal sympathetic response to cold stimulation in patients with Raynaud's phenomenon $(12,13)$. Rather interestingly we found that epinephrine was particularly low in patients with Raynaud's phenomenon. Few and controversial data on plasma epinephrine in this disease have been published $(14,15)$ and the physiological significance of plasma epinephrine is still not known even for healthy individuals (16). Since virtually all plasma epinephrine is derived from adrenal medullary tissue (17), and since adrenalectomized humans have low resting circulating epinephrine which increases after stimulation (18), with normal haemodynamic and plasma norepinephrine responses to the cold test (19), an impairment of adrenomedullary epinephrine secretion in Raynaud's phenomenon cannot be ruled out. However, since adrenalectomized persons are not at increased risk of vasospastic attacks, the low plasma epinephrine levels of our patients may be seen as an epiphenomenon. Since acetylcholine relased from parasympathetic nerves may play a part in regulation of the adrenal release of epinephrine (20) and since parasympathetic dysfunction in Raynaud's phenomenon has been reported (21), the low plasma epinephrine in our patients might be related to parasympathetic damage. Low values of epinephrine might be associated also with depression (22). On the other hand, it is not possible to rule out that low circulating epinephrine might compensate for some abnormality of sympatho-adrenal receptors $(23-25)$. The increased epinephrine found in patients during the cold test could indicate that this manœuvre was more stressful to those subjects who knew in advance that cooling would be particularly stressing. An increase of epinephrine is considered in fact to be the most sensitive neuroendocrine response to stress (26). The response of plasma dopamine to cold stimulation is particularly intriguing. The mechanism for the variation of dopamine levels is unknown, mainly because the source of circulating dopamine has not yet been clearly established $(27,28)$. While dopamine changes observed in controls during the cold test are in accord with those in previous studies (29), there is little information on measurement in the recovery phase following sympathetic stimulation, although dopamine levels have been found to be unchanged after bicycle exercise and cross-country march (30). The different behaviour of dopamine vs norepinephrine and epinephrine $30 \mathrm{~min}$ after the cold test observed in our controls suggests that circulating dopamine has a role of its own and does not represent a mere reserve for circulating norepinephrine and epinephrine (27); in accord with this, we saw no correlation between the levels of dopamine and those of norepinephrine and epinephrine. Since dopamine has been hypothesized to be involved in vasodilatation $(31,32)$, it is tempting to speculate that circulating dopamine might be a physiological mediator for post-ischaemic vasodilatation. However, because of the variable dopamine increase in controls during the recovery phase, the physiological importance of the small but significantly different dopamine behaviour between patients and controls, which we found in the recovery phase, is still unclear.

In conclusion, the normal plasma norepinephrine pattern observed in patients would indicate a normal sympathetic response to cold stimulation in Raynaud's phenomenon, while the abnormal plasma epinephrine might be consistent with higher stress rating in patients. The changes in circulating dopamine might indicate that dopamine plays a role in post-ischaemic vasodilatation, a role which would be impaired in patients with Raynaud's phenomenon. Further evidence is necessary to evaluate the physiological role of dopamine in the post-ischaemic vasodilatation.

This work is supported in part by "Gruppo Nazionale Cardiorespiratorio" C. N. R., Rome. 


\section{References}

1. Raynaud, M. (1862) De l'asphyxie locale et de la gangrène simetrique des extrémités; Thèse de Paris. Nouvelles rechèrches sur la nature et le traitment de l'asphyxie locale des extrémités. Archive générale de Médicine 23, 5-21; $189-206$.

2. Duff, R. S. (1952) Effect of sympathectomy on the response to adrenaline of the blood vessels of the skin in man. J. Physiol. 117, 415-430.

3. Fries, J. F. (1969) Physiologic studies in systemic sclerosis (scleroderma). Arch. Intern. Med. 123, 22-25.

4. Fagius, J. \& Blumenberg, H. (1985) Sympathetic outflow to the hand in patients with Raynaud's phenomenon. Cardiovasc. Res. 19, 249-253.

5. Allen, E. V. \& Brown, G. E. (1932). Raynaud's disease: a critical review of minor requisites for diagnosis. Am. J. Med. Sci. 183, 187-200.

6. Subconmittee for Scleroderma Criteria of the American Rheumatism Association: Diagnostic and Therapeutic Criteria (1980) Preliminary criteria for the classification of systemic sclerosis (scleroderma). Arthritis Rheum. 23, $581-590$.

7. Marasini, B., Biondi, M. L. \& Agostoni, A. (1987) Circulating dopamine in Raynaud's phenomenon. Angiology 28, $878-882$.

8. Saar, R. \& Gordon, R. D. (1979) Variability of plasma catecholamine levels: age, duration of posture and time of day. Br. J. Clin. Pharmacol. 8, 353-358.

9. Folkow, B., Di Bona, G. F., Hjemdal, P., Toren, P. H. \& Wallin, B. G. (1983) Measurements of plasma norepinephrine concentrations in human primary hypertension. Hypertension 5, 399-403.

10. Floras, J., Jones, J. V., Hassan, M. O., Osikowska, B. A., Sever, P. S. \& Sleight, P. (1986) Failure of plasma norepinephrine to consistently reflect sympathetic activity in humans. Hypertension 8, 641-649.

11. Lenders, J. W. M., Willemsen, J. J., De Boo, T., Lemmens, W. A. J. \& Thien, T. (1989) Disparate effects of mental stress on plasma noradrenaline in young normotensive and hypertensive subjects. J. Hypertension 7, 317-323.

12. Peacock, J. H. (1959) Peripheral venous blood concentration of epinephrine and norepinephrine in primary Raynaud's disease. Circ. Res. 7, 821-827.

13. Nielsen, S. L., Christensen, N. J., Olsen, N. \& Lassen, N. A. (1980) Raynaud's phenomenon: peripheral catecholamine concentration and effects of sympathectomy. Acta Chir. Scand. 302, 57-62.

14. Kontos, H. A. \& Wasserman, A. J. (1969) Effect of reserpine in Raynaud's phenomenon. Circulation 39, 259-266.

15. Sapira, J. D., Rodnan, G. P., Scheib, E. T., Klaniecki, T. \& Rizk, M. (1972) Studies of endogenous catecholamines in patients with Raynaud's phenomenon secondary to progressive systemic sclerosis (scleroderma). Am. J. Med. 52, $330-337$.

16. Editorial (1985) The function of adrenaline. Lancet $i, 561-$ 562.
17. Guyton, A. C. (1981) The autonomic nervous system; the adrenal medulla, In: Textbook of Medical Physiology, (6th ed.), pp 710-722, W. B. Saunders Company, Philadelphia.

18. Hoelzer, D. R., Dalsky, G. P., Schwartz, N. S., Clutter, W. E., Shah, S. D., Holloszy, J. O. \& Cryer, P. E. (1986) Epinephrine is not critical to preyention of hypoglycemia during exercise in human. Am. J. Physiol. 25, E104-110.

19. Lenders, J. W. M., Peters, J. H. M., Pieters, G. F. F. Willemsen, J. J. I. \& Thien, T. N. (1988) Hemodynamic reactivity to sympathoadrenal stimulation in adrenalectomized women. J. Clin. Endocrinol. Metab. 67, 139-143.

20. Peyrin, L. \& Dalmar, Y. (1975) La sécrétion et l'inactivation périphériques des catécholamines. J. Physiol. (Paris) 70, $353-433$.

21. Klimiuk, P. S., Taylor, L., Baker, R. D. \& Jayson, M. I. (1988) Autonomic neuropathy in systemic sclerosis. Ann. Rheum. Dis. 47, 542-545.

22. Christensen, N. J. (1988) Psychosocial stress and catecholamines: their relationship to aging, duodenal ulcer, hypo= condriasis and hypertension. Pharmacol. \& Toxicol., Suppl. $1,24-26$.

23. Jamieson, G. G., Ludbrook, J. \& Wilson, A. (1971) Cold hypersensitivity in Raynaud's phenomenon. Circulation 44, $254-264$.

24. Lefkowitz, R. J. (1979) Direct binding studies of adrenergic receptors: biochemical, physiologic and clinical implications. Ann. Intern. Med. 91, 450-458.

25. Vanhoutte, P. M. \& Janssens, W. J. (1980) Thermosensitivity of cutaneous vessels and Raynaud's disease. Am. Heart. J. $100,263-264$.

26. Wortsman, J., Frank, S. \& Cryer, P. E. (1984) Adrenomedullary response to maximal stress in humans. Am. J. Med. $77,779-784$.

27. Van Loon, G. (1983) Plasma dopamine: regulation and significance. Fed. Proc. 42, 3012-3018.

28. Eldrup, E., Hagen, C., Christensen, N. J. \& Olgaard, K. (1988) Plasma free and sulfoconjugated dopamine in man: relationship to sympathetic activity, adrenal function and meals. Dan. Med. Bull. 35, 291-293.

29. Wolf, P. D., Akowuah, E. S., Lee, L., Kelly, M. \& Feibel, J. (1983) Evaluation of dopamine response to stress in man. J. Clin. Endocrinol. Metab. 56, 246-250.

30. Ratge, D., Gehrke, A., Melzner, I. \& Wisser, H. (1986) Free and conjugated catecholamines in human plasma during physical exercise. Clin. Exper. Pharmacol. Physiol. 13, $543-553$.

31. Goldberg, L. I. (1984) Dopamine receptors and hypertension. Physiologic and pharmacologic implication. Am. J. Med. 77, 34-44.

32. Kaiser, C. \& Jain, T. (1985) Dopamine receptors: functions, subtypes and emerging concepts. Med. Res. Anat. 5, 145229.

Bianca Marasini, MD

Clinica Medica, Ospedale S. Paolo

via di Rudini 8

I-20142 Milano 